\title{
A MULHER E A POLÍTICA NO CONTINUUM DA QUALIFICAÇÃO EPISTÊMICA
}

\author{
The Woman and the Politics in the Epistemic Qualification Continuum
}

\author{
Aline Rodrigues dos SANTOS \\ Universidade Estadual de Maringá \\ alineunisintonia@gmail.com \\ https://orcid.org/0000-0002-5743-119X
}

\begin{abstract}
RESUMO: O objetivo desta pesquisa é analisar a manifestação da modalidade epistêmica na constituição da posição sujeito das candidatas à vice-presidência da república. As perguntas e respostas recortadas do corpus referem-se ao debate político que ocorreu no dia 28 de setembro de 2018, entre as candidatas à vice-presidência do Brasil das eleições desse mesmo ano. As perguntas e respostas selecionadas têm como temática a participação da mulher na política, já que tal debate é um acontecimento histórico e discursivo por ser o primeiro que reuniu o significante número de quatro mulheres candidatas, ao que a mídia denominou "onda de vices mulheres". Foi possível observar que a maioria delas, na maior parte das vezes, inscreve seus enunciados em baixos graus de comprometimento e no nível das possibilidades, já que a participação feminina na candidatura ao cargo de vice-presidente em número tão significativo ainda era algo inédito e a posição sujeito mulher política se faz e se fez nos entremeios dos espaços público e privado.
\end{abstract}

PALAVRAS-CHAVE: Modalidade Epistêmica; Funcionalismo; Discurso; Mulheres.

\begin{abstract}
The goal of this research is to analyze the epistemic modality manifestation in the subject position constitution of the candidates for the republic vice presidency. The questions and answers taken from the corpus refer to the political debate that happened on September 28, 2018, among the candidates for the Brazil's vice presidency in the elections that same year. The selected questions and answers theme refer to the women participation in politics, since this debate is a historical and discursive event because it is the first that brought together the significant number of four women candidates, to what the media called "wave of vice women". It was possible to observe that most of them, in most cases, inscribe their statements in low degrees of commitment and in the possibilities level, since the participation of women in the candidacy for the position of vice president in such a significant number stills unprecedented and the subject position of political women was and has been between public and private spaces.
\end{abstract}


KEYWORDS: Epistemic Modality; Functionalism; Discourse; Women.

\section{INTRODUÇÃO}

O debate político entre as candidatas à vice-presidência do Brasil das eleições de 2018 (ocorrido no dia 28 de setembro deste mesmo ano) constitui o corpus de análise deste trabalho. O evento foi promovido pelo jornal El País e pelo Instituto Locomotiva Pesquisa e Estratégia e foi transmitido ao vivo pelas redes sociais dos organizadores. No entanto, aqui será utilizado o que se encontra disponível no canal Mídia Ninja do YouTube (https://www.youtube.com/watch?v=glOeZ0FR8qg). As participantes do debate são, em ordem alfabética: Ana Amélia Lemos (do Partido Progressista - PP), Kátia Regina Abreu (do Partido Democrático Trabalhista - PDT), Manuela Pinto Vieira D’ávila (do Partido Comunista do Brasil - PCdoB) e Sônia Bone Guajajara (do Partido Socialista PSol).

Nesse sentido, apresenta-se o objetivo da pesquisa: analisar a manifestação da modalidade epistêmica na constituição da posição sujeito das candidatas à vicepresidência da república. E, apresentado o objetivo principal, é necessário explanar que, apesar de essa constituição de sujeito se dar no e pelo discurso político, o objetivo, ao analisá-lo, não é observar a modalidade epistêmica funcionando no discurso político em si ${ }^{1}$, mas na produção do sujeito mulher candidata à vice-presidência diante da chamada "onda de vice mulheres" (assim denominado o número expressivo de mulheres que pleiteavam esse cargo pelas jornalistas que participaram do debate).

Esse contexto (a onda) é imprescindível para o procedimento metodológico e analítico das duas abordagens que compõem o eixo teórico deste trabalho: a abordagem funcionalista - principalmente a partir de Dall'aglio-hattnher (2001) e Halliday (1970 1985) -, que estuda a língua em uso em seus níveis pragmático, semântico e sintático,e a

\footnotetext{
${ }^{1}$ Outros trabalhos já analisaram a modalidade epistêmica no discurso político e já atestaram seu caráter persuasivo que favorece o aparecimento dos valores epistêmicos. Este artigo já parte deste princípio, o discurso político se vale desta modalidade. Por isso, o interesse aqui volta-se para a análise das relações que constituem o sujeito (mulher candidata à vice-presidência) nesse discurso. DALL'AGLIO-HATTNHER, M. M. A manifestação da modalidade epistêmica: um exercício de análise nos discursos do ex-presidente Collor. 1995, 146f. Tese (Doutorado em Estudos Lingüísticos e Língua Portuguesa) - Universidade Estadual Paulista, Araraquara.
} 
abordagem da Análise do Discurso de linha francesa (doravante AD), que estuda o discurso enquanto prática - de perspectiva foucaultiana (2008 - 2014).

Há de se ressaltar ainda, que, perseguindo o objetivo principal e o recorte contextual acima citados, as perguntas e respostas recortadas do debate para este trabalho são as que diretamente têm a participação da mulher na política e, não raras as vezes, a participação das mulheres nas eleições nacionais de 2018 como temas.

Sublinha-se, já em instância introdutória, que o sujeito mulher brasileira candidata à vice-presidência da república qualifica seu discurso, na maioria das vezes, sem se comprometer com a verdade do que diz quando se trata do referente participação da mulher na política. Inscrevendo seus enunciados no campo das possibilidades, esse sujeito se revela um sujeito do entremeio: um lugar ainda por se consolidar inteiramente na política partidária nacional pelas vias do protagonismo feminino.

\section{NOS ENTREMEIOS DO PRIVADO E DO PÚBLICO EMERGE O SUJEITO MULHER}

O direito ao voto feminino no Brasil tem pouco mais de 80 anos. Até o alcance dessa conquista, em 1932, as sufragistas brasileiras lutaram antes e de depois da redemocratização pelo exercício do poder político partidário. Em 1910, o primeiro partido feminino foi criado - O Partido Republicano Feminino (PRF) -, liderado por Leolinda Daltro. Em 1927, no estado do Rio Grande do Norte, registrou-se a primeira eleitora brasileira, Celina Guimarães Viana. Esta também foi a eleição em que o voto feminino sofreu sua primeira anulação pela Comissão de Poderes do Senado Federal. Dois anos depois, o mesmo estado elegeu a primeira mulher brasileira, Luzia Alzira Teixeira Soriano, ao cargo de prefeita da cidade de Lajes, em 1929. Em 2010, a primeira mulher é eleita presidenta da república. Em 2014, Dilma Vana Rousseff tornou-se também a primeira mulher reeleita ao mesmo cargo. Em 2016, Rousseff sofre o segundo impeachment da história da República Federativa do Brasil.

De saída, essa breve contextualização das inaugurações femininas na política partidária do país desvela a dificuldade em constituir-se nessa ordem: entre datas, votações, eleições, anulações e destituições, percebe-se que as mulheres entram com mais dificuldade nos cargos em comparação aos homens. Tal contextualização mostra também 
que a participação no sistema eleitoral brasileiro tem menos de um século, porém a atuação política das mulheres irrompe em todos os períodos históricos do Brasil. Scott (1992, p. 95) argumenta que "a história das mulheres é um campo inevitavelmente político", entendendo política como "as relações de poder, os sistemas de convicções e práticas" e é dentro dessa perspectiva que este trabalho compreende o conceito de política, para além das ações partidárias.

Sobre o conceito de sujeito, para a AD, a emergência de uma posição sujeito, remete à lei singular do aparecimento dos enunciados na e pela história (FOUCAULT, 2008, p. 148), e não sem antes entrarem em uma relação de forças. Portanto, nesse escopo, é preciso mostrar como se dá a constituição discursiva das subjetividades que se distribuem no social, mostrando "à luz do dia o jogo da rarefação imposta, com um poder fundamental de afirmação" (FOUCAULT, 2014, p. 66).

Dentro do que é proposto por Michel Foucault, principalmente nas obras $A$ Arqueologia do Saber (2008) e A Ordem do Discurso (2014), pode-se afirmar que a AD é um campo de pesquisa que dispõe sobre as materialidades das linguagens com o objetivo de compreender os sentidos em sua produção social por sujeitos históricos. A possibilidade de compreender a produção social dos sentidos se dá por ser o discurso uma prática que constitui os objetos e os sujeitos. O discurso seria, então, uma prática social diretamente ligada à formação dos saberes e à instituição das verdades. Desta forma, descrever seu funcionamento e, assim, compreender seus efeitos de sentido é possível na medida em que os enunciados, formando conjuntos, regularizam o que deve ou não ser dito.

Um sujeito denominado feminino, ou mulher ${ }^{2}$ ou, até mesmo, candidata à vicepresidência da república, por exemplo, existe por determinadas regras de formação do próprio discurso que se autorregulamenta em meio a relações de poder para dizer e compreender esse sujeito do modo como deve ser dito e compreendido. Essas regras de formação dão condições de existência, manutenção e transformação à produção e

\footnotetext{
${ }^{2}$ Apesar do uso do termo "mulher", no singular, é fundamental destacar que este trabalho o toma em sua pluralidade, na esteira do que explica Scott (1992, p. 87): “(...) o termo 'mulheres' dificilmente poderia ser usado sem modificação: mulheres de cor, mulheres judias, mulheres lésbicas, mulheres trabalhadoras pobres, mães solteiras, foram apenas algumas das categorias introduzidas. Todas desafiavam a hegemonia heterossexual da classe média branca do termo 'mulheres', argumentando que as diferenças fundamentais da experiência tornaram impossível reivindicar uma identidade isolada".
} 
organização dos enunciados que comportam os objetos e sujeitos (FOUCAULT, 2008, p.43). Por isso, a relação íntima do discurso com o poder de dominação e com a verdade: ele pré-determina as posições sujeito e as relações que elas podem estabelecer entre si, nas palavras de Foucault:

Ele aparece como um bem - finito, limitado, desejável, útil - que tem suas regras de aparecimento e também suas condições de apropriação e de utilização; um bem que coloca, por conseguinte, desde sua existência (e não simplesmente em suas "aplicações práticas"), a questão do poder; um bem que é, por natureza, o objeto de uma luta, e de uma luta política (FOUCAULT, 2008, p. 43).

Nesse sentido, a língua evidencia posições sujeito pela sua própria estrutura. No entanto, um enunciado, ao constituir a materialidade da língua,ancora-se na história e na memória, entra em relação com outros enunciados, institui posições sujeito não apenas na estrutura, mas em sua singular irrupção que estabelece condições de apropriação e de utilização desse dizer formando, num mesmo gesto, a história do presente, de modo que, descrever sua lei de aparecimento e entender sua regularidade, requer uma análise imbricada de saber-poder para chegar aos seus trajetos de sentido.

Recuperar história e memória para compreender a lei de aparecimento da produção discursiva de sujeitos femininos na política requer, de fato, um grande empreendimento que não cabe no espaço do qual dispõe este trabalho. Entretanto, algumas relações saberpoder que atravessam história e memória podem ser revisitadas no intuito de apontar algumas condições de aparecimento - e até mesmo de existência - do discurso político que tem como referente o feminino, para que se possa embasar as análises dos possíveis trajetos de sentido, bem como a análise da materialidade linguística em abordagem funcionalista que atribui igual importância aos sentidos e contextos de uso da língua.

Nesse âmbito, a perspectiva do discurso feminista constituindo subjetividades em direção a modos mais livres de existência, nos últimos anos, é muito discutida. Margareth Rago (1998), por exemplo, expõe que

Há uma construção cultural da identidade feminina, da subjetividade feminina, da cultura feminina, que está evidenciada no momento em que as mulheres entram em massa no mercado, em que ocupam profissões masculinas e em que a cultura e a linguagem se feminizam. As mulheres 
entram no espaço público e nos espaços do saber transformando inevitavelmente estes campos, recolocando as questões, questionando, colocando novas questões, transformando radicalmente. (RAGO, 1998, p.10).

De fato, há uma construção cultural, social e linguística que, em muitos aspectos, é radicalmente - emprestando o termo de Rago - outra atualmente. Ao questionar as identidades e o gênero, o movimento feminista, enquanto acontecimento discursivo e histórico, transformou vários campos (do conhecimento, da economia, da política etc.). Novamente, recorre-se à Rago (1998, p. 10) que expõe: “com todas as suas dificuldades e limitações, o feminismo criou um modo específico de existência, muito mais integrado e humanizado".

No entanto, esse contexto do presente relatado por Rago (1998), ao mesmo tempo, dissipa um passado mais invisível das mulheres, principalmente na política, e desvela uma atual e insistente luta por igualdade nesse campo. Alguns trechos das perguntas recortadas para análise podem comprovar isso:

a) “...a representação feminina no congresso é de $10 \%$, é uma limitação! Por que que isso acontece?"

b) “...senadora, $46 \%$ das eleitoras ainda não decidiram seu voto, segundo as pesquisas espontâneas..."

Evidentemente agindo dentro de maiores espaços de liberdade, mas definitivamente longe do patamar de igualdade, as mulheres brasileiras ainda se encontram na luta pela conquista de maior participação política tanto no nível partidário (no caso das candidatas) quanto no nível mais ligado ao tecido social (no caso das eleitoras). E isso se deve, entre outras coisas, às maneiras como mulheres e homens são e foram historicamente produzidos em espaços públicos e privados.

A divisão sexual do público e do privado, longe de ser um reflexo da sociedade industrial que provocou a segmentação 'o trabalho para o homem e a família para a mulher', é uma prática discursiva atravessada pela história, entendida como aquilo que constitui o sujeito e o saber (FOUCAULT, 2008, p. 11), e produzida por discursos econômicos, da medicina, midiáticos, religiosos e, especialmente, políticos. Dizeres sobre o corpo feminino o ligavam incessantemente ao emocional, ao inferior, ao materno, 
sentimental e, consequentemente, ao lar. Rago (1998, p. 13-14) argumenta: "a história do corpo feminino trouxe à luz as inúmeras construções estigmatizadoras e misóginas do poder médico, para o qual a constituição física da mulher por si só inviabilizaria sua entrada no mundo dos negócios e da política".

Além disso, o “processo de privatização da família”, como chamou D’Incao (2012, p. 224-225), produziu, em toda a malha social, dizeres e sentidos em torno da inferioridade feminina, bem como da inferioridade do privado. O conceito de intimidade, na formação da sociedade burguesa, embora tenha funcionado de formas diferentes entre as classes sociais, cristalizou-se em todas elas. Nas classes mais altas, "a ideia de intimidade se ampliava e a família, em especial a mulher, submetia-se à avaliação e opinião dos outros... Essas mulheres tiveram de aprender a comportar-se em público, a conviver de maneira educada" (D'INCAO, 2012, p. 228). Nas classes mais baixas, economicamente impedidas de se recolherem ao privado, as mulheres dependiam do trabalho fora de casa, "sempre por baixo de uma hierarquia profissional, e estabelecendo seus salários em níveis insuficientes para sua subsistência” (SCOTT, 1991, p. 428 apud RAGO, 1998, p. 7).

Os dois parágrafos acima são um breve aporte de práticas discursivas, entre tantas outras, de dizeres formados entre saberes e poderes sobre o feminino. Práticas essas que constituem as leis de formação dos discursos atuais sobre as mulheres no lar e no público. Mesmo que um evento discursivo - o debate - entre mulheres candidatas seja possível hoje, este mesmo evento demonstra as práticas discursivas que perduram de um passado logo atrás entre sujeitos femininos dentro do campo da política:

c) "As mulheres decidem seus votos na reta final da campanha eleitoral, por estarem em processo de avaliação das políticas públicas em áreas vitais do cotidiano. As mulheres pensam em como são as principais usuárias da área de saúde, é... educação, transporte etc.”

d) "As mulheres, normalmente, defendem áreas difíceis de serem financiadas, as mulheres defendem muito área social, a questão da mulher, a questão dos mais pobres, a questão da saúde. E quem quer financiar isso?"

e) “...Então nós temos que continuar insistindo, pra que eles tenham a percepção clara da nossa relevância, não apenas como eleitoras, mas como agenda fundamental de quanto mais mulheres na política, nas decisões, seja no poder executivo e nos demais poderes, vai mudar a compreensão e uma sociedade mais solidária e mais humana, porque essa é a atitude que têm as mulheres." 
Nestes trechos de duas das questões e de uma das respostas que compõem o material de análise, no que diz respeito ao eixo temático 'mulher na política', observa-se que, entre candidatas e eleitoras, áreas ligadas ao cuidado familiar são as que mais interessam às mulheres. Observa-se também como as políticas direcionadas à família ainda são inferiorizadas no sistema político brasileiro. Quando a AD teoriza o discurso como prática, é dessas práticas que instituem verdades que ela diz. Neste caso, verdades materializadas na linguagem colocam o sujeito feminino na política de forma muito diferente do que o masculino. No conflitante poder entre colocar a mulher no privado e quebrar essas barreiras para a conquista do público, vê-se, como regularidade deste discurso, um espaço de liberdade conquistado, em meio a formas de sujeitos femininos ainda muito ligadas ao lar, constituindo seu lugar na política a partir de discursos e verdades que as fazem direcionar interesses às políticas ligadas ao âmbito familiar.

Retomando Scott (1992, p. 95), reafirma-se que a história das mulheres é inevitavelmente ligada do político, mas um político que se faz nos entremeios da luta por sair ao público e, no mesmo gesto, tornar o privado também político.

\section{A MODALIDADE EPISTÊMICA}

A discussão feita por Dall'aglio-hattnher et al. (2001) sobre a modalidade epistêmica, no texto Uma investigação funcionalista da modalidade epistêmica, elenca diferentes perspectivas dentro do enfoque funcionalista em relação a essa categoria.

Quanto à definição das modalidades, o trabalho apresenta um ponto de encontro entre as teorias funcionalistas: "é forçoso admitir seu papel de veiculadoras das atitudes do falante com relação ao que é dito" (DALL'AGLIO-HATTNHER et al., 2001, p. 01).

Já sobre a diversidade de perspectivas teóricas, tal publicação parte de Halliday (1970-1985) que, em suas considerações a partir das análises das modalidades, identifica três funções da linguagem - ideacional, interpessoal e textual - dentro da multiplicidade de usos; e, em suas reconsiderações teóricas, revê alguns pontos problemáticos na identificação dessas funções diante da diversidade dos atos de fala. As modalidades, para ele, "estão dentro do componente interpessoal mas, ao mesmo tempo, estão orientadas no sentido do ideacional, uma vez que expressam um posicionamento do falante em relação ao conteúdo da oração" (DALL'AGLIO-HATTNHER et al., 2001, p. 05). 
Assim, nos estudos convergidos entre Halliday (1985), Dik (1989) e Hengeveld (1988), a modalidade epistêmica se aplica ao mundo interno (psicológico) e indica as possibilidades intermediárias de significação entre os eixos do negativo e do positivo, portanto, negações e afirmações, expressos nas proposições e que perpassam os graus da probabilidade e da habitualidade. Nas palavras de Hengeveld: "todos aqueles meios lingüísticos pelos quais o falante pode expressar seu comprometimento em relação à verdade da proposição" (HENGEVELD, 1988, p. 234 apud DALL'AGLIO-HATTNHER et al., 2001, p. 10). Trata-se, dessa forma, dos usos linguísticos que expressam o conhecimento sobre um determinado estado de coisas (EC) e que envolvem o julgamento e o envolvimento do falante em relação a esse conhecimento expresso.

Metodologicamente, nessa perspectiva, a qualificação modal subjetiva pode ser observada a partir da camada da proposição e a qualificação modal objetiva pode ser observada a partir da camada da predicação. Os modalizadores epistêmicos são, pois, segmentados entre os que expressam atitudes proposicionais, e assumem função representadora do conteúdo de um ato de fala (ex.: "gente sabe que o Brasil mudou muito nos últimos anos..." / "Eu acho que esse dado é fundamental..."), e os que expressam atitudes de predicação em relação à realidade de um EC e assumem, assim, função designadora (ex.: “...certamente, as mulheres foram protagonistas dessas mudanças...”) (DALL'AGLIO-HATTNHER et al., 2001, p. 13).

É coerente afirmar, então que "o calibrador da certeza/ não certeza é o conhecimento, que compromete o falante com a verdade das declarações" (NEVES, 2002, p.188), no entanto, além dos conhecimentos e crenças, as autoras elencam outro aspecto a ser levado em conta no estudo da avaliação epistêmica: a evidência. A evidencialidade está presente como categoria gramatical da modalidade epistêmica já que ela constitui implícita ou explicitamente a informação dada pelo falante que escolhe colocar-se como fonte ou pressupões que tal informação é compartilhada.

Dall'aglio-hattnher e as demais autoras da publicação de 2001 propõem, então, uma ampliação na análise para que a separação entre as modalidades epistêmica subjetiva e objetiva não seja tão estanque, e nem a separação da própria modalidade da evidencialidade, pois elas podem assumir "diferentes funções na situação de interação": 
Ao qualificar epistemicamente uma proposição, o falante não só a avalia como certa ou possível mas também se posiciona com relação a essa avaliação. Nesse caso, é a função interpessoal da frase que está sendo encarecida. Ao qualificar epistemicamente um estado-de-coisas, o falante descreve esse estado-de-coisas como certo ou possível, sem contudo manifestar sua posição com relação a essa avaliação. E, nesse caso, é a função representacional da frase que está sendo encarecida (DALL'AGLIO-HATTNHER, 1995, p. 131 apud DALL'AGLIOHATTNHER et al., 2001, p. 19, grifo das autoras).

Até porque, a função objetiva e a função subjetiva nem sempre podem ser distinguidas no uso diário da língua (LYONS, 1977, s/p apud GUIRALDELLI, 2011, p. 357).

Abaixo, apresentam-se alguns exemplos para que seja possível observar as relações de subjetividade, objetividade e evidencialidade na modalidade epistêmica no sentido que orienta as autoras. A fala é retirada do mesmo texto do qual o corpus de análise foi recortado, porém, pertence à representante da Locomotiva Pesquisa e Estratégia, que faz a introdução ao debate das mulheres candidatas à vice-presidência:

f) (1'08'):"' juntamos alguns dados e alguns levantamentos da Locomotiva e vamos trazer aqui pra vocês... A gente sabe que o Brasil mudou muito nos últimos anos e, certamente, as mulheres foram protagonistas dessas mudanças... Em 20 anos, o número de mulheres chefes de família, no Brasil, passou de $22 \%$ para $45 \%$ [...]"

A falante qualifica seu compromisso com a verdade ao descrever o EC pelo uso do advérbio certamente - função representacional -, mas também avalia e se posiciona, ao qualificar a proposição como certa, no uso do verbo saber- função interpessoal. Compreende-se, ainda, que a separação estanque entre qualificação objetiva e subjetiva, se empreendida aqui, deixa de considerar a evidência, ancorada, principalmente, no conhecimento elaborado a partir do estudo científico quantitativo (dados e levantamentos) o qual embasa a fala da representante do instituto que conduziu o estudo e que lhe dá condições de dizer no âmbito da certeza.

g) (12' 25”): “[...] 20\% das mulheres, na espontânea, ou seja, quando não são lidos os nomes dos candidatos e candidatas, falam que votarão branco ou nulo e $26 \%$ que ainda não sabem, ou seja, $46 \%$ das mulheres não citam nenhum candidato espontaneamente... Eu acho que esse dado é fundamental, porque, em que pese haver mulheres e opções de voto, o 
que tá sendo dito pelas candidaturas não casa com o que essas mulheres..."

O verbo achar, qualificador da modalidade epistêmica, nesse contexto, e entre outras coisas, revela que a falante ora se compromete mais, ora menos. Ora escolhe explicitar a evidencialidade, ora não. Isso quer dizer que é importante reconhecer que, em certa medida, há uma segmentação entre as funções da qualificação objetiva e da qualificação subjetiva, no entanto, é necessário reconhecer o continuum entre a certeza e o possível. É fundamental observar também que a modalidade epistêmica é do mundo psicológico e que, metodologicamente, certos usos podem ser privilegiados, mas sem perder de vista que, na língua em uso, os limites das definições conceituais podem se misturar.

\section{A QUALIFICAÇÃO EPISTÊMICA NOS DIZERES DA MULHER POLÍTICA}

O debate político entre as candidatas à vice-presidência da república, no ano de 2018, constitui um acontecimento discursivo diante do relevante grau de ineditismo pelo número de mulheres a ocupar tal posição sujeito - "a onda de vices mulheres", como denominou a imprensa. Nesse sentido, é importante observar a modalização discursiva dessas mulheres ao falarem de si mesmas e do lugar que ocupam - candidatas a um alto cargo -, tendo em vista que esse cargo político ainda é um lugar em construção para o sujeito feminino conforme discutido na primeira seção do trabalho.

A tabela abaixo é um levantamento numérico dos elementos modalizadores para a observação de como se distribuem nas respostas às perguntas recortadas.

Tabela 1: Modalizadores de Certeza e de Possibilidade

\begin{tabular}{|l|c|c|c|c|c|c|}
\hline & $\begin{array}{c}\text { Resposta } \\
01\end{array}$ & $\begin{array}{c}\text { Resposta } \\
02\end{array}$ & $\begin{array}{c}\text { Resposta } \\
03\end{array}$ & $\begin{array}{c}\text { Resposta } \\
04\end{array}$ & $\begin{array}{c}\text { Resposta } \\
05\end{array}$ & Total \\
\hline $\begin{array}{l}\text { Modalizadores } \\
\text { de possibilidade }\end{array}$ & 04 & 04 & 05 & 03 & 05 & 21 \\
\hline $\begin{array}{l}\text { Modalizadores } \\
\text { de certeza }\end{array}$ & 01 & 01 & - & 01 & 02 & 05 \\
\hline
\end{tabular}

Fonte: elaborada pela autora, 2020. 
Foram escolhidas, pois, questões tematizadas por esse lugar em construção, questionamentos feitos pelas jornalistas presentes e que têm como tópico a mulher na política.

A primeira questão que aborda a temática foi feita pela jornalista Sônia Racy (O Estado de S. Paulo). A pergunta é mais abrangente e compreende a participação da mulher na política em sentido mais amplo, não apenas como candidatas, também como eleitoras:

1. (27'34"): “...em 1910, essa data (Dia das Mulheres) foi novamente comemorada, mas a favor do voto da mulher. Isso significa que nós estamos há 110 anos combatendo desigualdades. Eu queria saber: somos nós mulheres as incompetentes? E, nesse caso, quem é que vai empoderar a gente?"

1.1 Resposta de Sonia Guajajara (28'48”): "Nós não somos incompetentes, de forma alguma. Acho que nós fomos sempre as mais humilhadas, as mais oprimidas por conta de um sistema machista herdado do colonialismo que deixou muita violência, que matou muitas mulheres, que exterminou muitos povos [...] É um momento de luta, o momento de nos unirmos e eu acho que quem vai acabar com essa invisibilidade e quem vai acabar, ainda, com todo esse papel secundário que querem o tempo todo impor sobre nós, somos nós mesmas [...]"

1.2 Comentário de Manuela D'ávila (30'44") "Eu acredito que quem nos empodera somos nós mesmos e nós vivemos num tempo, e creio que esse tempo une as várias lutas de todas as mulheres, porque tudo o que a gente conquistou até aqui foi com muita luta, né, a luta pelo voto, a luta contra a escravidão das mulheres negras [...]"

A resposta de Sonia Guajajara sobre a incompetência da mulher é uma proposição na qual ela expressa comprometimento com a verdade do que diz em forma de negação, utilizando-se da locução adverbial (de forma alguma) como recurso linguístico. No entanto, tanto Guajajara quanto D'ávila migram para os sentidos da opinião, a primeira, e da crença, a segunda, quando a indagação é sobre quem empodera as mulheres na política.

A segunda questão foi feita pela jornalista Rejane de Oliveira, do jornal El país, que contextualizou sua pergunta a partir do impeachment da presidenta Dilma Roussef, em 2016. O então vice-presidente assume e apresenta uma linha governamental diferente do que Roussef propunha. A figura do vice passa por algumas ressignificações: 
2. (31'53”): “... Há alguma negociação sobre como será o seu papel num futuro governo Geraldo Alkmin? Algo entre ser uma vice decorativa ou uma vice com um projeto pessoal de poder?"

2.1 Resposta de Ana Amélia (32’20"): "Pra quem saiu de casa aos nove anos de idade, filha mais velha de uma família pobre, sabe que não há submissão que me imponha qualquer regra, desde que eu reconheça, nesse caso da vice-presidência, que eu tenho que seguir aquilo que a Constituição determina das prerrogativas que compete ao vicepresidente. Já disse ao presidente Geraldo Alkmin que não serei uma vice decorativa e a agenda das mulheres é uma das prioridades na nossa pauta de atuação... Tivemos um encontro com a Maria da penha lá em Fortaleza e percebemos que a questão relacionada a esta agenda do machismo e da submissão das mulheres, ela tá muito vinculada a uma questão cultural e é exatamente aí que, talvez resida o nosso maior desafio: é mudar esta cultura de submissão da mulher a uma vontade do homem ... Então, eu penso que nós temos um caminho muito grande... É um trabalho muito grande que vamos fazer como compromisso de campanha com o presidente Geraldo Alkmin."

2.2 Comentário de Kátia Abreu (34’05”): “...Então, eu penso que Ciro Gomes tem dito, em várias oportunidades, que nós nos completamos e essa é a verdade [...] E quero dizer também a todas as mulheres que a vice-presidência da república é... no nosso mandato... será uma embaixada das causas da mulher brasileira."

No continuum entre a certeza e a não certeza, Ana Amélia compromete-se mais quando responde sobre seu papel em uma possível eleição. A candidata ancora seu dizer em si mesma, cita a si mesma como fonte de sua proposição e envolve-se mais com seu dizer. Mas quando direciona sua fala para a agenda das mulheres e para os caminhos que deverão ser seguidos para superar desafios e formular pautas, ela vai se distanciado da certeza pelo uso do verbo no subjuntivo associado ao advérbio modalizador talvez até chegar na instância da opinião - com o verbo pensar.

Kátia Abreu, por sua vez, faz o caminho contrário, ela busca a referência explícita ao candidato de sua chapa além de utilizar o verbo de significação plena na manifestação da modalidade epistêmica no campo da crença quando se refere ao lugar que ocupará em um possível governo, apesar de afirmar que a declaração do candidato à presidência é verdadeira. Já, em relação às pautas femininas, afirma, mesmo sem explicitar a fonte de seu dizer, que estarão no patamar de embaixada no caso de eleição.

A terceira pergunta recortada foi feita pela jornalista Sônia Racy novamente e indaga sobre a pequena porcentagem de mulheres candidatas a cargos políticos em geral, 
visto que há uma cota, garantida por lei, de $30 \%$ de participação feminina nos partidos e que não é preenchida e, frequentemente, os partidos recorrem a "candidatas laranjas".

3. (51'27”): “...Por que se nós somos só $10 \%$ do congresso e a lei exige uma cota de $30 \%$ das candidatas e os partidos não conseguem preencher essa cota, usam candidatas laranjas... o que você acha disso? Nós não estamos querendo participar da política?"

3.1 Resposta de Kátia Abreu (55'06”): “...agora, eu acho que nós teremos uma diferença fundamental. Agora ficou, como diz o dito popular: agora ficou todo mundo japonês, todo mundo igual, certo? Então. Agora, tem que ir à luta! O dinheiro é pouco pra todo mundo, o tempo de televisão ainda é uma dificuldade, mas eu acho que ficou em bases melhores, porque os homens que tinham nos segmentos econômicos com mais facilidade de financiamento, agora também estão no mesmo jogo das mulheres. Então, eu acredito que agora as mulheres vão se sentir mais encorajadas porque não há uma candidata que não saiba que tem direito a esse dinheiro. Então, agora sim, eu acho que as coisas podem mudar. E agora entra a nossa parte. Nós temos que procurar as candidatas mulheres e votar, né, gente?! Também não vamos tirar nossa parcela de responsabilidade."

3.2 Comentário de Sonia Guajajara (55’06”): “É, bom... Eu quero dizer aqui que estou muito orgulhosa de estar participando de uma chapa em um partido, uma coligação PSOL e PCB, onde tem... É uma coligação que tem o maior número de mulheres candidatas concorrendo nessas eleições 2018, que são muito, muita presença de mulher, mulher feminista, né, também o partido que mais tem aí a presença da diversidade como candidatas."

Kátia Abreu faz uma análise a partir da questão econômica ao considerar a ruptura no sistema até então vigente. O financiamento privado, que privilegiava as pautas masculinas em detrimento das femininas teve fim e o financiamento público passou a reger as candidaturas. Naquele momento, tal reconfiguração ainda estava por se fazer de modo que a senadora joga no campo da crença e da opinião - acreditar e achar - sobre o futuro envolvimento feminino com os partidos em face dessa mudança. Observa-se que não há alto grau de comprometimento do sujeito com o que diz, Abreu não dá como certo o envolvimento das mulheres (ponto central da questão) tanto que, no período "eu acho que as coisas podem mudar", o estado de coisa encontra-se no nível da possibilidade verbo auxiliar modal - e a avaliação, no nível da incerteza.

Já Sonia Guajajara tece seu comentário tendo sua coligação como referencial, um 
referencial mais restrito em comparação com a escolha de Kátia Abreu e do qual ela tem um elevado grau de conhecimento. A candidata aponta fatos relacionados à formatação e articulação de seu partido e de sua candidatura. Desta forma, qualifica seu discurso com alto grau de comprometimento com o que diz, age discursivamente no fio da verdade, mesmo escolhendo não marcar linguisticamente a evidencialidade de seu dizer.

Já questionadas sobre a participação feminina na política, sobre a participação individual em suas respectivas candidaturas, sobre a participação feminina na política partidária brasileira, a jornalista Jacira melo, da Agência Patrícia Galvão, questiona o papel da mulher especificamente na campanha de 2018 , tendo em vista a chamada "onda de vices mulheres".

4. ( (1 ${ }^{\circ} 14^{\prime} 02^{\prime}$ '): “...46\% das eleitoras ainda não decidiram seu voto... Que que tá acontecendo ainda com as campanhas, as mulheres vices, que foi essa onda que nós tivemos, ainda não estão conseguindo influenciar as campanhas?"

4.1 Resposta de Ana Amélia ( $1^{\circ} 15$ '26"): "Muito obrigada pela pergunta, essa é a pergunta mais repetida e porque que não aparecemos mais na televisão. Eu penso que já o espaço que estamos ocupando, no meu entendimento, já é uma percepção clara, dos candidatos das coligações, sobre trazer as mulheres para um protagonismo."

4.2 Comentário de Sônia Guajara (1¹6'56”): "Bom, eu considero um avanço, já bem significativo também, essa presença das mulheres nas chapas presidencial e também o número de mulheres candidatas né, pras assembleias, aliás, pros governos estaduais, né, assim também como a presença das mulheres que estão aí pras assembleias legislativas, pro congresso nacional. É claro que a gente tem muita luta pra fazer pela frente..."

Nas proposições relativas à "onda", as candidatas as qualificam epistemicamente pelo uso de verbos de significação plena indicadores de opinião (pensar e considerar). Essas proposições constituem um acontecimento inédito na política brasileira e, por isso, são avaliadas no campo da possibilidade/não certeza, inclusive no uso da locução adverbial (nо meu entendimento) a qual Ana Amélia recorre para reiterar sua avaliação. Ambas as avaliações coincidem diante da dificuldade de asseverar um contexto que ainda estava se construindo (que é a forte participação feminina nas candidaturas a altos cargos) e, além disso, diante de um contexto que comprometia diretamente a todas: a possibilidade 
de pouca influência feminina nas campanhas mesmo diante da referida "onda".

Sobre essa pouca influência, a candidata Sônia Guajajara descreve como certa a luta para revertê-la pelo uso do adverbial claro. É a qualificação epistêmica de um estadode-coisa. Um EC que constitui, ao contrário da "onda", um contexto já formado, que é a "luta" das mulheres pela influência e participação efetiva na política, sempre liderada e formada majoritariamente pelos homens. É necessário aqui atentar-se a essa ideia de certeza em relação a "luta", pois ela confirma a citada pouca influência, sinal do silenciamento da história feminina nesses lugares de (macro) poder.

A última pergunta recortada para este estudo, ainda da jornalista Jacira melo, faz referência a uma política de afirmação existente em alguns países e importante para entender seu questionamento e as respostas das candidatas:

5. (1²9’00'): “Senadora, os países que adotaram ações afirmativas para alcançar a paridade de mulheres nas casas legislativas, adotaram um sistema de cotas para mulheres eleitas e não para candidaturas de mulheres. Nos partidos políticos brasileiros, que a gente pode dizer o mínimo que são misóginos, ou clube de bolinhas, para ser mais suave, e um congresso com $90 \%$ de parlamentares homens, como é possível enfrentar essa enorme distorção, onde nós temos um país em que somos mais de $50 \%$ da população e menos de $10 \%$ de mulheres? E mais, no estado de São Paulo, nós temos médios municípios... Jacira, Jacira Melo... no estado de São Paulo, nós temos médios municípios que não têm sequer uma mulher vereadora."

5.1 Resposta de Kátia Abreu (1 ${ }^{\circ} 29^{\prime} 57^{\prime}$ '): “Jacira, é uma ideia maravilhosa! Um desafio enorme, mas não é impossível. Acho super interessante, gosto muito...é... acho que é uma nova possibilidade que se abre. [...] Mas gosto muito, eu acho que é uma forma de reverter rapidamente. E quero registrar, que, se fosse o contrário, $80 / 90 \%$ de mulheres e $10 \%$ de homens, também não seria correto para o equilíbrio de gênero, para que as leis possam ser complementadas com os dois sentimentos... então, eu acho que essa seria uma solução pra nós levarmos aos canditados a presidente e eu espero que o meu chegue lá pra poder propor essa mudança. Obrigada."

5.2 Manuela D'Ávila (1³1'26'): "Eu defendo isso, né. Há bastante tempo, minha militância é marcada por isso, inclusive, tentamos, num último esforço de reforma política, incluir uma espécie de transição, né, não chegar, automaticamente a 50\% das vagas, mas 20\% das vagas, $25 \%$ das vagas. Mas pra além disso, Jacira, meu mestrado, eu vou entregar domingo e é só sobre isso: participação de mulheres e efetividade do aumento de políticas pras mulheres quando a mulher é gestora, não quando é parlamentar, mas nós precisamos, então, falar sobre quais 
mulheres nós queremos eleger, né. A gente precisa ampliar o número de mulheres, e isso nos garante qualidade democrática, garante representatividade ao conjunto de opiniões na voz das mulheres, mas, para a maior parte das mulheres brasileiras, não adianta eleger qualquer mulher..."

Kátia Abreu mostra desconhecimento sobre a proposta de ação afirmativa apresentada pela jornalista. Sendo assim, não podendo asseverar sobre algo que acabou de tomar consciência da existência, avalia a proposição utilizando o verbo achar, de significação plena, para expressar sua opinião sobre a proposta. A senadora mostra-se favorável ao modelo apresentado pela jornalista, tanto que expressa expectativa/desejo/esperança de poder apresentá-lo diante de uma possível eleição de sua chapa.

Ao contrário de Kátia Abreu, Manuela D’ávila conhece o modelo de cotas referenciado e, por isso, não se utiliza de comprometimento fraco como a senadora. A candidata marca-se linguística e discursivamente como fonte de seu dizer (eu defendo/meu mestrado) e essa marcação ela faz em boa parte de sua resposta como recurso para assegurar a confiabilidade daquilo que ela diz. Na segunda parte da resposta, ela não marca linguisticamente a evidencialidade do seu dizer, talvez porque pressupunha que o conhecimento sobre o que diz seja compartilhado pelos interlocutores (...a maior parte das mulheres brasileiras é negra, recebe um salário baixo e precisa de um Estado que invista em políticas públicas...).

\section{CONCLUSÃO}

A modalidade epistêmica desvela o comprometimento ou, principalmente nos casos analisados neste estudo, o nível do descomprometimento do falante com a verdade do enunciado, bem como sua atitude e avaliação. Observa-se que, quando se refere à participação da mulher na política, na maioria das falas das mulheres candidatas há pouca marca ou reforço de compromisso epistêmico relativo ao conteúdo proposicional e/ou estado-de-coisas, conforme a tabela 01 e as análises desenvolvidas na seção anterior.

Majoritariamente, as falas aqui analisadas transitam entre o não-comprometimento, o não-conhecimento e o possível. Isso, sem dúvida, deve-se, entre outras coisas, a dois aspectos: às projeções de situações futuras e hipotéticas que enfrentarão, caso vençam as 
eleições, e ao atravessamento histórico tanto do silenciamento quanto da luta feminina na política. É importante compreender que um aspecto está imbricado no outro, situações futuras e hipotéticas se apresentam de diferentes formas a mulheres e homens diante do referente participação política. Para isso, é necessário atentar-se ao teor das questões recortadas do debate, questões que indagam: "somos incompetentes?", “quem vai nos empoderar?", “não estamos querendo participar da política?”, "não estão conseguindo influenciar as campanhas?”. Questões que as condições históricas contemporâneas já não permitem que sejam produzidas em contextos de debates políticos entre homens brancos candidatos à presidência e/ou vice-presidência da república, mas que direcionam as respostas analisadas aqui.

Como já foi discutido, o discurso político, quando tem o feminino como referente, ainda é terreno de entremeio, com algumas verdades cristalizadas, mas muito ainda em vias de se fazer. Além disso, nas eleições presidenciais de 2018, a chamada "onda de vices mulheres" se apresentava como um contexto inédito na história o que também influenciou no nível de comprometimento das candidatas. Tal ineditismo não está na participação da mulher na política em si. Dois anos antes, em 2016, Dilma Roussef, a primeira mulher presidenta da república, sofria um processo de impeachment que refletiu na forma como a sociedade pensa a mulher em alto cargo de representatividade pública e, consequentemente, em como as próprias mulheres se pensam nesse lugar. O ineditismo citado se dá no número de mulheres pleiteando, pontualmente, a vice-presidência do país.

Estudos da modalidade epistêmica do discurso político que tem o homem em posição sujeito mostram que tais discursos tendem a ser mais assertivos e categóricos, jogam com a persuasão, objetivam o convencimento e a construção de imagem de segurança do candidato e, por isso, tendem a ter um teor mais alto de comprometimento com o dizer. A título de exemplificação, cita-se a pesquisa de Guiraldelli (2011).

No discurso político que tem a mulher em posição sujeito, a modalidade epistêmica pode, da mesma forma, funcionar com alto grau de comprometimento no trabalho da construção persuasiva. No entanto, especificamente neste estudo, dentro das questões recortadas e das respostas analisadas, tendo como referente a participação da mulher na política, a partir dos dizeres das quatro candidatas à vice-presidência da república, é possível compreender que tal posição sujeito se constituem entre a luta: a) para sair do 
privado, âmbito ao qual saberes e poderes ligaram o feminino como lugar de construírem "as virtudes femininas de submissão e silêncio, nos comportamentos e gestos cotidianos" (PERROT, 2003, p. 16), que deveriam ser centrais nas mulheres; b) para conquistarem o público: influenciar, participar e empoderar; c) para tornarem o privado - tanto o sentimental, quanto o prático: educação, saúde da família, assistência social etc. - também político e, consequentemente, tratado com a mesma importância que outros segmentos da política do masculino

A análise da manifestação da modalidade epistêmica na constituição dessa posição sujeito candidata à vice-presidência da república trouxe à luz esse sujeito do entremeio, que linguisticamente ainda se distancia do comprometimento com a verdade do que diz ao qualificar seu discurso quando fala de seu próprio lugar na política. Questionar essas subjetividades e observar a construção linguística de seus discursos é importante, entre outras coisas, para a compreensão da atualidade. Indo nesse sentido, Rago (2008) argumenta:

Está em jogo, nesse sentido, ao referir-se às 'estéticas da existência', a pergunta pelo modo como as mulheres contribuíram e contribuem para a construção de novos valores e códigos éticos, ajudando a atualizar o imaginário político e cultural de seu tempo (RAGO, 2008, p. 187).

O recorte analisado aqui, enquanto acontecimento discursivo por compor um debate político, ao conter enunciados, em maior parte, no campo do possível, revela regras e normas formadas e determinadas pelo modo de vida (das brasileiras e dos brasileiros) em relação à mulher na política, de modo que a união teórico-analítica da $\mathrm{AD}$ e da abordagem funcionalista mostra que, na estrutura da linguística, muito se tem dos sujeitos e da história.

\section{REFERÊNCIAS}

DALL'AGLIO-HATTNHER, M. M. et al. Uma investigação funcionalista da modalidade epistêmica. Laboratório Editorial FCL UNESP/ Cultura Acadêmica, Editora: Maria Helena de Moura Neves, 2001, p.103-143. Disponível em: $<$ https://www.researchgate.net/publication/281861711_Uma_investigacao_funcionalista_d a_modalidade_epistemica>. Acesso em: 16 mar. 2020. 
D'INCAO, M. Â. Mulher e família burguesa. In, DEL PRIORE, M (Org.). História das mulheres no Brasil. 10.ed. São Paulo: Contexto, 2012, p. 223-240.

FOUCAULT, M. A arqueologia do saber. Trad. Luiz Felipe Baeta Neves. 7.ed. Rio de Janeiro: Forense Universitária, 2008.

Loyola, 2014.

A ordem do discurso. Trad. Laura Fraga de Almeida Sampaio. 24.ed. São Paulo:

GUIRALDELLI, L. A. A modalidade epistêmica nos discursos políticos. Nucleus, v.8, n.2, 2011, p. 353-368.

HALLIDAY, M. A. K. Functional Diversity in Language as Seen from a Consideration of Modality and Mood in English. Foundations of Language, v.6, n.3, 1970, p. 322-361.

An Introduction to Functional Grammar. London: Edward Arnold. 1985.

PERROT, M. Os silêncios do corpo da mulher. In: MATOS, M. I.; SOIHET, R. (Orgs.). $O$ corpo feminino em debate. São Paulo: Editora UNESP, 2003, p. 13-27.

RAGO, M. Epistemologia feminista, gênero e história. In: PEDRO, J. M. e GROSSI, M. P. Masculino, feminino, plural gênero na interdisciplinaridade. Florianópolis: Editora Mulheres, 1998, p. 21-41.

Novos modos de subjetivar: a experiência da organização Mujeres Libres na Revolução Espanhola. Estudos Feministas, Florianópolis, 16 (1), 2008, p. 187-206.

SCOTT, J. História das Mulheres. In: BURKE, P. (Org). A escrita da história: novas perspectivas. Trad. Magda Soares São Paulo: Editora da Universidade Estadual Paulista, 1992, p. 63-96.

Recebido em: 05 jun. 2020.

Aceito em: 05 ago. 2020. 